\title{
A Pilot Study To Compare Using Verion Imaging Guided System (Alcon) To Manual Marking In Assisting LRI (Limbal Relaxation Incision) To Reduce Cylinder Power In Cataract Surgery
}

\author{
Ming Chen $^{1 *}$, Zachary Seagrave ${ }^{2}$, Thomas Patrianakos ${ }^{2}$, Surendar Dwarakanathan ${ }^{2}$, John J.
} Chen $^{3}$

${ }^{1}$ Department of Surgery, University of Hawaii, Honolulu, Hawaii 96813, USA

${ }^{2}$ Department of Ophthalmology, John H. Stroger, Jr. Hospital of Cook County, Chicago, Illinois 60612, USA

${ }_{3}^{3} J o h n$ A. Burns School of Medicine, University of Hawaii Honolulu, Hawaii 96813, US

Received: 24 October, 2016; Accepted: 02 November, 2016; Published: 12 November, 2016

*Corresponding author: Ming Chen, Department of Surgery, University of Hawaii, 55 S. Kukui St. C-109 Honolulu, Hawaii 96813, USA; E-mail: mingchen@hawaii.rr.com

\section{Abstract}

Aim: The aim of this study is to examine the cylinder power change by comparing the use of eye markings made manually with those aided by an image-guided system (Verion) after LRI (limbal relaxation incision) in cataract surgery for astigmatism correction.

Method: Setting: Surgical Suite, Hawaii, USA

Design: Retrospective comparative study. Thirty eyes from 30 consecutive patients with cataracts and low corneal astigmatism had LRI during phacoemulsification were included. Fifteen eyes had placement of LRI with eye markings manually and fifteen eyes had LRI with eye markings guided by Verion Image System. The changes in cylinder power were found and the mean of these changes were calculated for comparison.

Results: The mean absolute change in cylinder between the groups was 0.78 in the manual group and 0.98 in the Verion group $(p=0.63)$. The mean relative percent change in cylinder was $49.1 \%$ and $55.8 \%$ in the manual and Verion groups respectively.

Conclusion: LRIs made with eye imaging guided system such as Verion compared favorably with manual marking in correcting cylinder in cataract surgery.

Keywords: Limbal relaxation Incision; Cataract surgery; Cylinder

\section{Introduction}

Uncorrected distance visual acuity is the most predictive outcome of patient satisfaction following cataract surgery. This is best achieved with emmetropia and a spherical aberration of zero $[1,2]$. Multiple phases of cataract surgery from preoperative measurements and calculations to surgical incisions and lens positioning can potentially affect the final visual outcome after cataract extraction.
Recent studies have suggested that emmetropia after cataract extraction is attained in $55 \%$ of patients within plus or minus 0.50 diopter (D). Sixty to seventy percent of patients have half a diopter or more of astigmatism, and approximately $40 \%$ have at least $1 \mathrm{D}$ of astigmatism after cataract extraction [3-5]. It is now well known that treating or simply reducing even lower orders of astigmatism during cataract extraction leads to better visual outcomes and improved patient satisfaction. The benefits of astigmatism correction, whether preexisting or surgically induced, with cataract refractive surgery should be discussed in terms of the patient's goals for visual quality.

Corneal astigmatism in cataract surgery can be corrected with toric IOL implantation, limbal relaxing incisions (LRI) or a combination of the two [4,13]. Newer toric IOL are continuously being brought to the market with successful long-term results and clinical nomograms are making LRI results even more reliable [6]. Peripheral corneal arcuate incisions or LRI has proven to be a safe, effective and stable procedure for reducing corneal astigmatism during phacoemulsification $[7,8]$. However, one case of endophthalmitis was reported associated with LRIs [9]. Despite the technique being well within the skill set of cataract surgeons, LRI has been slowly adopted. LRI appears most suitable for management of low astigmatism, whereas greater levels of astigmatism are likely best treated by use of toric lenses with or without the addition of arcuate incisions. Additionally, LRIs correct the astigmatism at the source within the cornea, making them potentially effective for asymmetric corneal astigmatism where toric lenses are unable to benefit [10]. Even the long- term higher-order aberration was not altered by the LRI [11].

As cataract patients set higher expectations for surgical outcomes, every aspect that truly contributes to a more accurate 
and predictable final refraction need to be optimized. In toric IOL calculation, carefully measure the preoperative corneal astigmatism can avoid most of the error [12]. The importance of proper identification of the axis of astigmatism in toric IOL positioning is clear but the significance of precise alignment of arcuate incisions is less well known. Hirnschall et al indicated in their study that a high eccentricity of the cornea, a large deviation between keratometry and topography, and a high preoperative astigmatism resulted in a larger postoperative astigmatism correction error after LRI [13-14]. One study compared toric IOL to astigmatic keratotomy in correcting astigmatism during phacoemulsification and demonstrated the better outcomes of toric IOLs [15]. In the study that compare multifocal toric IOL and multifocal IOL with LRI, the toric IOL still showed more predictable than LRI in multifocal IOLs [16]. Recently, LRI can also be performed by Femtosecond laser in laser assisted cataract surgery $[17,18]$. Despite the accuracy of the optical coherence tomography-guided LRI with femtosecond laser, there was a case report of corneal perforation [19]. As axis orientation has an effect on visual performance in astigmatic eyes [20], marking the axis of astigmatic eye is paramount for the astigmatic correction. Using manual techniques may not account for slight head tilt deviations that can occur during acquisition of keratometry as well as later on during relocation of axes prior to making the LRI. This potential discrepancy of eye orientation between initial measurement and subsequent identification of reference points is an error that is addressed with the use of image-guided systems like Verion. Verion registers landmarks on the eye captured with a high definition picture and can track the exact location of the steep meridian of the patient's eye in relation to these landmarks intraoperatively. This is displayed in real-time as a digital overlay in the microscope eyepiece or LenSx unit. The system, which accounts for cyclorotation and tracks for eye movement, provides an accuracy in making incisions, creating the capsulorhexis, and aligning the IOL.

The aim of this study is to examine the cylinder power change comparing the use of eye markings made manually with those aided by an image-guided system before astigmatism correction using peripheral arcuate corneal incisions in a single surgeon's practice and nomogram following cataract extraction. This study has been approved by the IRB of the University of Hawaii.

\section{Subjects and Method}

This retrospective study involved thirty eyes of thirty consecutive patients from Sep, 2014 to March 2015 with visually significant cataracts and corneal astigmatism who underwent astigmatic correction with LRI during phacoemulsification/ cataract extraction. Exclusion criteria included pupil smaller than $3 \mathrm{~mm}$ before dilation, cornea irregularity from previous ocular trauma or surgery including previous kerato refractive surgery or from cornea surface disease like dry eye, previous inflammation or infection of the eye, and concurrent ophthalmic diseases other than cataract that limited the patient's vision. Fifteen eyes had placement of LRI with eye markings made manually and fifteen eyes had LRI with eye markings guided by Verion Image Guided System. All surgeries were performed by one surgeon (MC) and his known surgically induced astigmatism of 0.25 diopters against the rule was applied tohis LRI nomogram to account for the surgeon's technique.

The group with LRI placement directed by manual eye markings had refraction measured preoperatively using automated refractor and BCVA obtained using Snellen eye chart. Keratometry using IOL Master was measured and the steep meridian axis found was utilized as the center of LRI whose length and diameter were calculated with the surgeon's nomogram [Table 1]. On the day of surgery, slit-lamp was used to mark the 90 degree axis with a marking pen prior to dilate the pupil and being transported into the operating room suite. Prior to cataract extraction, the center of LRI was identified using the previously marked reference point. The LRI was then made using diamond blade according to LRI calculations determined preoperatively. Refraction was determined with auto refraction and manifestation postoperatively. Vision, cylinder power and axis were recorded for each eye pre-op and post-op.

The group with eye markings made with use of Verion also had refraction obtained preoperatively using automated refractor and BCVA obtained using Snellen eye chart after manifestation. Keratometry was found with IOL master and the specifications for LRI were calculated using the steep axis found with Verion using the surgeon's nomogram. The LRI was then made using diamond blade according to LRI calculations determined preoperatively following the marking and metrics showed on the cornea under microscope from the Verion's imaging.

Means and standard deviations were used to summarize patients' age and baseline clinical characteristics (e.g., preoperativecylinder and keratometry) for each group. Descriptive statistics for postoperative cylinder, the absolute and relative percent changes in cylinder were also calculated for each group. The two groups were then compared using two-sample t-tests for continuous variables.

\section{Results}

Mean (standard deviation) of patient age in manual and Verion eye marking groups was 68.1(5.9) years (range 55-77) and 65.3 years (5.6) (range 56-79) respectively $(\mathrm{p}=0.20)$. Mean (standard deviation) preoperative cylinder was $1.40(0.71)$ in the manual

\begin{tabular}{|l|l|l|l|}
\hline \multicolumn{2}{|l|}{ Table 1: Surgeon's Nomogram } \\
\begin{tabular}{|l|l|l|} 
With the \\
rule:
\end{tabular} & +0.75 & +1.00 & +1.50 \\
\hline Treatment & none & $\begin{array}{l}30 \text { degree } \\
x 1,9 \mathrm{~mm}, 90 \% \\
\text { depth }\end{array}$ & $\begin{array}{l}30 \text { degree } \mathrm{x} 2 \text { at } \\
9 \mathrm{~mm}, 90 \% \text { depth }\end{array}$ \\
\hline $\begin{array}{l}\text { Against the } \\
\text { rule }\end{array}$ & +0.75 & +1.00 & +1.50 \\
\hline Treatment & $\begin{array}{l}35 \\
\text { degreex1,8mm,90\% } \\
\text { depth }\end{array}$ & $\begin{array}{l}40 \\
\text { degreex1,8mm,90\% } \\
\text { depth }\end{array}$ & $\begin{array}{l}45 \\
\text { degreex1,8mm,90\% } \\
\text { depth }\end{array}$ \\
\hline
\end{tabular}

Age younger than 50 will add 5 degree more

Against the rule will enlarge half thickness wound to $3.5 \mathrm{~mm}$ at the temporal incision 
group and 1.37 (1.60) in the Verion group, ( $\mathrm{p}=0.954)$. Mean (standard deviation) of the average preoperative keratometry was 43.61(1.87) and 44.61(1.07) $(p=0.085)$ and the mean difference (standard deviation) in preoperative keratometry was $1.234(0.58)$ and $0.98(0.45)(\mathrm{p}=0.19)$ in the manual and Verion groups respectively (as Table 2 ). The mean (standard deviation) postoperative cylinder was $0.62(0.63)$ and $0.38(0.45)(p=0.26)$ in the manual and Verion groups respectively. The mean (standard deviation) absolute change in cylinder between the groups was $0.78(0.78)$ in the manual group and $0.98(1.38)$ in the Verion group $(\mathrm{p}=0.63)$. The mean relative percent change in cylinder was $56.0 \%$ and $72.0 \%$ in the manual and Verion groups respectively $(\mathrm{p}=0.70)$ [as Table 3 and Figure1].

\section{Discussion}

This study focus on the outcome of cylinder power reduction, therefore, vector analysis was not done. Besides, the mean cylinder power pre-op were only 1.40 and $1.37 \mathrm{D}$ respectively. The strength of this study is the two group's data were homogeneous with $\mathrm{P}>0.05$ and surgery were done by a single surgeon with the same nomogram. The weakness is not enough power for the study possible causing the difference in outcomes was not statistically significant. Nevertheless, LRIs made with eye markings guided by Verion resulted in an average astigmatic correction of $55.8 \%$ of the targeted correction compared to $49.1 \%$ with the manual technique. The result may indicate that a more accurate center axis marking with imaging guided system for limbal relaxation incision can result better cylinder correction similar in implanting toric IOL. Future study should be a prospective randomized large study to have enough power for a possible statistic significant result to prove the hypothesis.

\section{Conclusion}

LRIs made with eye imaging guided system such as Verion

\begin{tabular}{|l|r|l|l|}
\hline \multicolumn{5}{|c|}{ Table 2: comparison in age, pre-op cylinder and keratometry } \\
\hline & Manual & \multicolumn{1}{|c|}{ Verion } & p value \\
\hline $\begin{array}{l}\text { Age (years): mean } \\
\text { (Standard deviation)) }\end{array}$ & $68.1(5.9)$ & $65.3(5.6)$ & 0.20 \\
\hline $\begin{array}{l}\text { Preop cylinder: mean } \\
\text { (Standard deviation) }\end{array}$ & $1.40(0.71)$ & $1.37(1.60)$ & 0.954 \\
\hline $\begin{array}{l}\text { Average preop } \\
\text { keratometry: mean } \\
\text { (Standard deviation) }\end{array}$ & $43.61(1.87)$ & $44.61(1.07)$ & 0.085 \\
\hline $\begin{array}{l}\text { Difference in preop } \\
\text { keratometry: mean } \\
\text { (Standard deviation) }\end{array}$ & $1.23(0.58)$ & $0.98(0.45)$ & 0.19 \\
\hline
\end{tabular}

Table 3: Comparison in post-op cylinder

\begin{tabular}{|l|l|l|l|}
\hline $\begin{array}{l}\text { Mean postop cylinder } \\
\text { (Standard deviation) }\end{array}$ & $0.62(0.63)$ & $0.38(0.45)$ & 0.26 \\
\hline $\begin{array}{l}\text { Mean absolute change } \\
\text { in cylinder( standard } \\
\text { deviation) }\end{array}$ & $0.78(0.78)$ & $0.98(1.38)$ & 0.63 \\
\hline $\begin{array}{l}\text { Mean relative percent } \\
\text { change in cylinder }\end{array}$ & $56.0 \%$ & $72.0 \%$ & 0.70 \\
\hline
\end{tabular}

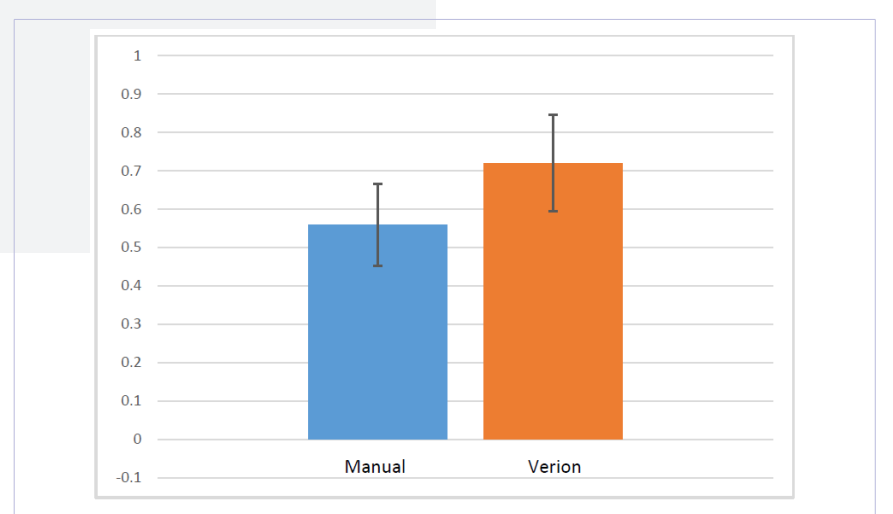

Figure1: Mean relative percent change in cylinder between the two groups

compared favorably with manual marking in correcting cylinder in cataract surgery.

\section{Acknowledgements}

Conflict of interest: Chen M, none; Seagrave Z, none; Patrianakos T, none; Dwarakanathan S, none Chen J, none

\section{References}

1. Lee ES, Lee SY, Jeong SY, Moon YS, Chin HS, Cho SJ, et al. Effect of postoperative refractive error on visual acuity and patient satisfaction after implantation of the Array multifocal intraocular lens. J Cataract Refract Surg. 2005;31(10):1960-1965.

2. Marques FF, Sato RM, Chiacchio BB, Marques DM, Barreiro J, Caetano RL. Evaluation of visual performance and patient satisfaction with pseudophakic monovision technique. Arq Bras Oftalmol. 2009;72(2):164-168.

3. Ferrer-Blasco T, Montés-Micó R, Peixoto-de-Matos SC, GonzálezMéijome JM, Cerviño A. Prevalence of corneal astigmatism before cataract surgery. J Cataract Refract Surg. 2009;35(1):70-75. doi: 10.1016/j.jcrs.2008.09.027.

4. Hill W. Expected effects of surgically induced astigmatism on AcrySof toric intraocular lens results. J Cataract Refract Surg. 2008;34(3):364367. doi: 10.1016/j.jcrs.2007.10.024.

5. Khan M, Muhtaseb M. Prevalence of corneal astigmatism in patients having routine cataract surgery at a teaching hospital in the united kingdom. J Catarac Refract Surg. 2011;37(10):1751-1755. doi: 10.1016/j.jcrs.2011.04.026.

6. Lim R, Borasio E, Ilari L. Long-term stability of keratometric astigmatism after limbal relaxing incisions. J Cataract Refract Surg. 2014;40(10):1676-81. doi: 10.1016/j.jcrs.2014.01.045.

7. Carvalho MJ, Suzuki SH, Freitas LL, Branco BC, Schor P, Lima AL. Limbal relaxing incisions to correct corneal astigmatism during phacoemulsification. J Refract Surg. 2007;23(5):499-504.

8. Price FW, Grene RB, Marks RG, Gonzales JS. Astigmatism reduction clinical trial: a multicenter prospective evaluation of the predictability of arcuate keratotomy. Evaluation of surgical nomogram predictability ARC-T Study Group. Arch Ophthalmol. 1995;113(3):277-82.

9. Haripriya A, Syeda TS. A case of endophthalmitis associated with limbal relaxing incision. Indian J Ophthalmol. 2012;60(3):223-225. doi: 10.4103/0301-4738.95879. 
10. Bradley MJ, Coombs J, Olson RJ. Analysis of an approach to astigmatism correction during cataract surgery. Ophthalmologica. 2006;220(5):311-316.

11. Monaco G, Scialdone A. Long-term outcome of limbal relaxation incisions during cataract surgery: aberrometric analysis. Clin Ophthalmol. 2015;9:1581-1587. doi: 10.2147/OPTH.S89024.

12. Himschall N, Hoffmann PC, DraschlP, Maedel S, Findl O. Evaluation of factors influencing the remaining astigmatism after toric intraocular lens implantation. J Refract Surg. 2014;30(6):394-400. doi: 10.3928/1081597X-20140429-01.

13. Hirnschall N, Wiesinger J, Draschl P, Findl O. Factors influencing efficacy of peripheral corneal relaxing incisions. J Ophthalmol. 2015;2015:706508. doi: 10.1155/2015/706508.

14. Hirnschall N, Gangwani V, Crnei A, Koshy J, Maurino V, Findl O. Correction of moderate corneal astigmatism during cataract surgery: toric intraocular lens versus peripheral corneal relaxing incisions. J Catarac Refract Surg. 2014;40(3):354-61. doi: 10.1016/j. jcrs.2013.08.049.

15. Titiyal J, Khatik M, Sharma N, Sehra S, Maharana P, Ghatak U, et al. Toric intraocular lens implantation versus astigmatic keratotomy to correct astigmatism during phacoemulsification. J Catarac Refract Surg. 2014;40(5):741-747. doi: 10.1016/j.jcrs.2013.10.036.

16. Gangwani V, Hirnschall N, Findl O, Maurino V. Multifocal toric intraocular lenses versus multifocal introcula lenses combined with peripheral corneal relaxing incisions to correct moderate astigmatism. J Catarac Refract Surg. 2014;40(10):1625-1632. doi: 10.1016/j. jcrs.2014.01.037.

17. Day A, Lau N, Stevens J. Nonpenetrating femtosecond laser intrastromal astigmatic keratotomy in eyes having cataract surgery. J Catarac Refract Surg. 2016;42(1):102-109. doi: 10.1016/j.jcrs.2015.07.045.

18. Ruckl T, Dexl A, Bachernegg A, Reischl V, Riha W, Ruckhofer J, et al. Femtosecond laser-assisted intrastromal arcuate keratotomy to reduce corneal astigmatism. J Catarac Refract Surg. 2013;39(4):528538. doi: 10.1016/j.jcrs.2012.10.043.

19. Cherfan D, Melki S. Corneal perforation by an astigmatic keratotomy performed with an optical coherence tomography-guided femtosecond laser. J Catarac Refract Surg. 2014;40(7):1224-1227. doi: 10.1016/j. jcrs.2014.04.021.

20. Kobashi H, Kamiya K, Shimizu K, Kawamorita T, Uozato H. Effect of axis orientation on visual performance in astigmatic eye. J Catarac Refract Surg. 2012;38(8):1352-1359. doi :10.1016/j.jcrs.2012.03.032 